\title{
Research on demand response control technology of building flexible load
}

\author{
Xuming Song ${ }^{\mathrm{a}}$, Jianyi Zhao, Wenjing Li, Peidong Duan and Jun Zheng \\ State Grid (Shagnhai) Smart Power Grids R\&D Investment Co. Ltd, Shanghai
}

\begin{abstract}
With the development of national energy-saving emission reduction and power demand side management and other related work, the building energy saving business has got a favorable policy foundation. In recent years, building internal flexible load resources are increasing, building users affected the concept of environmental protection and driven by the relevant incentive measures, the will of participating in demand response by the use of flexible load resources continue to increase. In order to support the flexible load of building to participate in demand response, this paper designed the building energy management system architecture, and proposed the classification method of building load. The regulation model of the central air-conditioning system and the distributed PV system is established, and the model of the demand response control strategy model for the typical flexible load of the building is formed. The system architecture, control strategy and regulation model formed in the paper carried out the application of the pilot in the development of building energy management system. The pilot applications prove that the system architecture design is reasonable, model function is perfect, it can satisfy the demand response regulatory requirements of building flexible load.
\end{abstract}

Keywords: building; flexible load; demand response; load control.

\section{Introduction}

The Chinese of coal-burning and car exhaust emission is generally considered as the culprit of smog and air pollution, but an important field is often overlooked, buildings consumes $41 \%$ of the global energy and occupies the $21 \%$ of the carbon dioxide emissions. With the Chinese urbanization, global warming, resources shortage, how to solve the problem of building energy efficiency will be a major research topic.

With the development of new energy technology and the continuous development of demand response technology, the role of the power terminal user is changing, the traditional rigid load users gradually show some flexibility [1-2]. Don't use the traditional blackouts method during peak periods and select demand response technology to alleviate the contradiction between supply and demand of electricity, reducing power consumption during peak periods, and having the significant cost benefits comparing to the cost of investing power installed capacity to meet peak power[3]. Flexible load can actively participate in the operation and control of the power grid and interact with the power grid, which has the flexible characteristic. In the building system, the load can be divided into four

acCorresponding author: 413501559@qq.com

(C) 2016. The authors - Published by Atlantis Press 
categories: uncontrollable load, interrupt load, adjustable load and transfer load. In this paper, the control mode of the flexible load is designed, and the control strategy of the flexible load participating in demand response is studied.

\section{Building energy management system}

BEMS is coordination, control and integration of building measurement system, automatic control system, distribution system, distributed power supply, air conditioning system, lighting system, etc. power supply system and building control system. It can monitor, analyze and control the user power supply system, energy load, DER, energy storage load, supporting the independent operation of the micro-grid, improving the user's energy efficiency, the system architecture as shown in Fig.1. The DER is small, modular energy production and storage technology, providing power or energy to where they are needed. DER may be connected to the local power grid, it may also be used independently of the local power grid isolation. Sub system has three functions of data acquisition and processing, grid information feedback and analysis. At the same time, BEMS develops strategy of energy consuming based on data acquisition, processing and analysis results of sub system, and achieves the remote control of each subsystem through the linkage control [4].

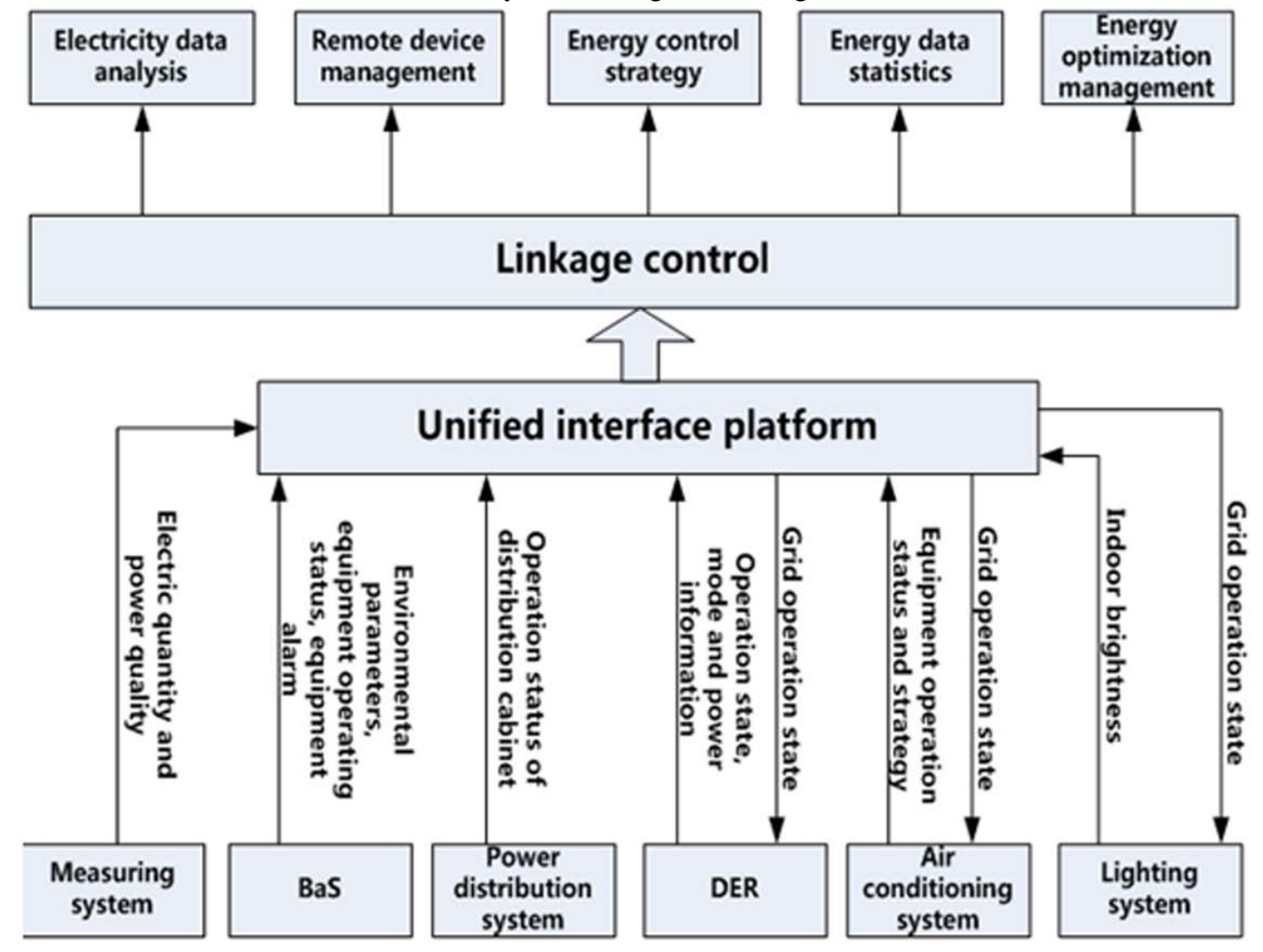

Figure 1.BEMS system architecture

\section{Typical load control mode}

To compare and analyze the data of building history and the current operation of the equipment, and get the load status of each time period. That is, the current operating parameters of the running load, 
such as the central air conditioning temperature, lighting intensity and the load on the open and close, etc.

Obtain building load characteristics, including operating power and equipment load time distribution characteristics, etc. According to the load characteristics, load can be divided into uncontrollable load, interrupt load, adjustable load and transfer load. In this paper, the typical uncontrollable load, such as DER (below the PV as a typical example of DER), fire power, etc. It needs to be pointed out here, PV in building systems is negative power of the electricity load participating in demand response and its power will be influenced by illumination intensity, illumination time and other uncontrollable factors. Interrupt load's power is not variable, with a larger power time, power distribution is more dispersed, such as conventional lighting, etc. Adjustable load's power is variable, short-term power outages do not affect the normal life of residents, it can participate in demand response which accepted in the range of comfort, such as central air-conditioning system. Transfer load's power is not variable, with constant power times, electricity load time distribution is more dispersed, such as water heater, etc.

\subsection{Control mode of central air-conditioning system}

According to the equipment of the empirical building, according to characteristic curve in different ways of air conditioning control validation building central air-conditioning system load adjustment, providing technology, effect and the user will data support for the research on key technology of air conditioning load control.

In the process of control, according to the local temperature and user comfort feedback, timely adjust the control mode. In this paper, the empirical study according to actual situation of the building, the central air-conditioning system can be controlled as follows.

(1)Control the start and stop of the host

During peak load period, the 1-2 platform is closed to reduce the electric load.

(2)Close some fresh air unit

During peak load period, close the fresh air units of each layer, reducing the power load.

(3)Control the opening degree of the water valve of the fresh air unit

During peak load period, control opening degree of water valve of the fresh air unit and adjust the air conditioning load to control the electric load.

(4)Close end fan coil

During peak load period, close end fan coil and reduce the cooling load demand to reduce the cooling load of the air-conditioning system.

(5)Use building space to store cold in advance

Based on the investigation and analysis of the building thermal insulation characteristics, the maximum load start time is determined, which ensures the user's bearing capacity, and maintains the minimum load operation of the air conditioning system during the peak period. As shown in Table1.

Table 1. Central air conditioning control mode

\begin{tabular}{|c|c|c|c|}
\hline $\begin{array}{l}\text { Controlled } \\
\text { equipment }\end{array}$ & \multicolumn{2}{|c|}{ Control mode } & Explain \\
\hline $\begin{array}{l}\text { Refrigerating } \\
\text { machine }\end{array}$ & $\begin{array}{l}\text { Control the start and stop of } \\
\text { the host }\end{array}$ & 3 controlled in 5 & $\begin{array}{l}\text { Cold and warm water } \\
\text { valve linkage, } 2 \text { controlled } \\
\text { in } 3 \text {, so } 2 \text { units } \\
\text { participate in the control }\end{array}$ \\
\hline \multirow{2}{*}{ Fresh air unit } & $\begin{array}{l}\text { Control the start and stop of } \\
\text { the fresh air unit }\end{array}$ & Stop every 2layers & \\
\hline & $\begin{array}{l}\text { Control the opening degree of } \\
\text { water valve }\end{array}$ & $\begin{array}{l}\text { Open every 2layers, } \\
\text { open } 50 \%, 80 \%, 20 \%\end{array}$ & \\
\hline Fan coil & Close part of fan coil & & \\
\hline
\end{tabular}




\subsection{PV system output model}

The output power of the building PV power generation device changes with the light intensity and the ambient temperature, and has strong nonlinear characteristics, and in cloudy weather, the output power changes rapidly in short time. Its output model is:

$$
\mathrm{P}_{\mathrm{pV}}^{\mathrm{t}}=\eta_{\mathrm{pV}} \mathrm{n}_{\mathrm{pV}} \mathrm{s}_{\mathrm{pV}} \mathrm{K}_{\mathrm{pV}}\left[1-0.005\left(\theta_{\text {out }}^{\mathrm{t}}-25\right)\right]
$$

In the formula: In the formula: $\mathrm{P}_{\mathrm{pV}}^{\mathrm{t}}$ is PV power output, $\eta_{\mathrm{pV}}$ is PV conversion efficiency of PV devices, $\mathrm{n}_{\mathrm{pV}}$ is the number of $\mathrm{PV}$ cell panel, $\mathrm{S}_{\mathrm{pV}}$ is $\mathrm{PV}$ cell panel area, $\mathrm{K}_{\mathrm{PV}}$ is solar radiation intensity, $\theta_{\text {out }}^{\mathrm{t}}$ is outdoor temperature.

\section{Demand response control strategy of flexible load}

In demand response event, according to the target load quantity given by grid and the history electricity data of building and environmental conditions, set the building comfort adjustable range, such as the air conditioning comfort degree can be accepted ranges of $24-28$ degree in summer, the specific value of the set is determined according to the specific circumstances of building load.

Because the power of the adjustable load device is large, and the influence of the comfort of the user is not obvious, the priority is to adjust the adjustable load, which can reduce the power of the user in the adjustable range. Secondly because of transfer load is flexible and has high power, effectively to achieve short-term peak clipping, regulate transfer load, in the transferable time range, is to change use time of electrical equipment. Finally, the interrupt load can be adjusted, that is, shut down the lowest use frequency interrupt load in the current period. Uncontrollable load can't be directly involved in the demand response control, but it needs to calculate the uncontrollable load into the given load target, such as PV systems, fire power, etc. It should be pointed out that, the PV system is negative power, according to the weather forecast and historical data, combining with the Eq.1 to estimate the power.

Each control of a kind of load, that is, a judgment of load target amount, if the regulatory plan meets the target volume requirements, the control scheme is formed, continue to carry out the control until all the load object is determined. If all the loads have participated, and not yet reached the target volume, then reset the control range of the maximum adjustable range, re-load regulation. The specific control strategy is shown in Fig.2. 
According to the comparative analysis of historical electricity data and current situation of equipment operation, get the different periods buildings load state of the equipment.

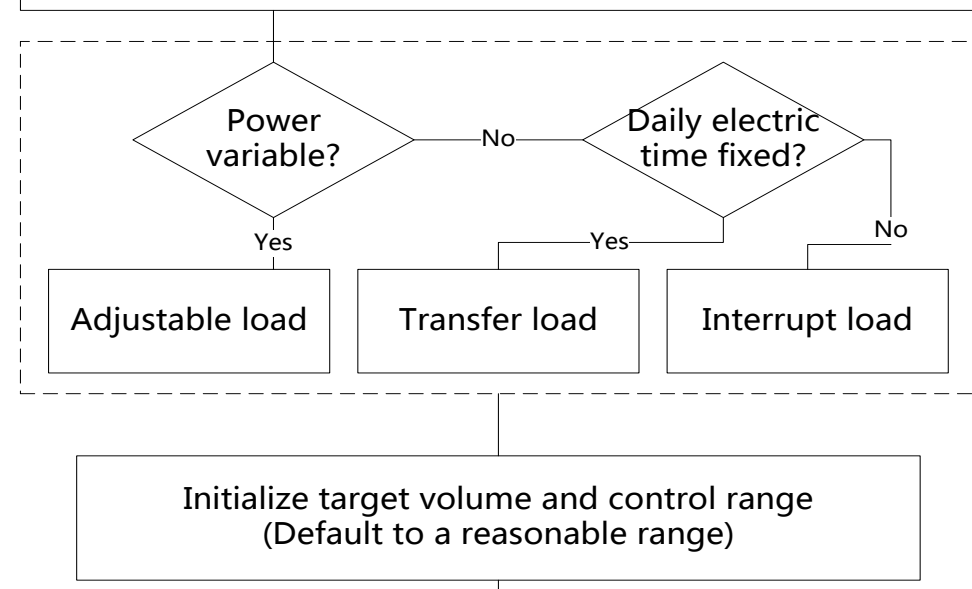

According to the demand of load target, adjust the adjustable load according to the setting regulation range

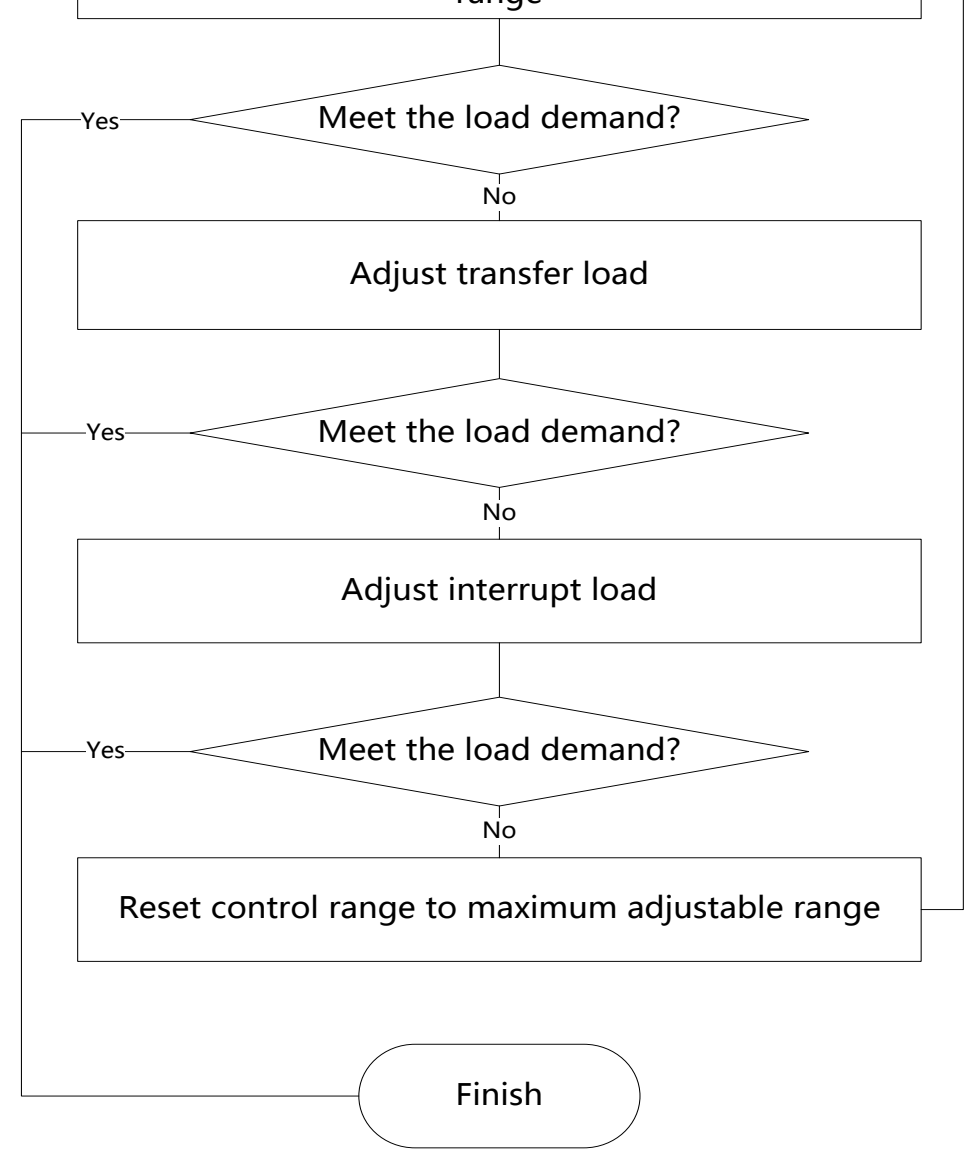

Figure 2. Flexible load control strategy 


\section{Summary}

In this paper, the load of buildings are classified, realizing level control of building load based on the load characteristics, compared to unified regulation or no single classification shut down equipment, it's more in line with the user's habits, and also more in line with the feasibility of actual consumption. In the process of load regulation, giving full consideration to the load use requirements of comfort, as the constraint condition of comfort, considering the historical electricity consumption habits and balance with demand for electricity and the power grid load demand, better reaches load control strategies for intelligent, automatic, humanization.

To solve the problem of building energy efficiency will greatly alleviate the energy crisis, to promote energy saving and emission reduction. At the same time, the building will also participate in demand response to balance the peak valley, ensure the safe and stable operation of power grid.

\section{References}

1. Faria P, Vale Z, Soares J, et al. Demand response management in power systems using a particle swarm optimization approach [J]. IEEE Intelligent System, 2013, 28 (4):43-51.

2. Jussi Ikaheimo, Corentin Evens, Seppo Karkkainen. DER aggregator business: the finish case [EB/OL]. http://www.ece.hut.fi/enete.

3. Ramirez-Escobar C, Alvarez-Bel C, Georgantzis N. Controlling market power of vertically integrated firms in electricity networks: demand response of aggregator agents [C]. 2011 IEEE PES Conference on Innovative Smart Grid Technologies, 2011:1-7.

4. Zhu Binruo, Zhang Shenming, Wang Hu. Realization Means of Integrated Energy-Saving Control in Intelligent Power Building [J]. Shanghai Energy Conservation, 2010, 4(3):39-43. 